\title{
Determination of the Dead Time of a Stopped-Flow Fluorometer ${ }^{1}$
}

\author{
Pierre Brissette, ${ }^{2}$ David P. Ballou, and Vincent Massey \\ Department of Biological Chemistry, The University of Michigan, Ann Arbor, Michigan 48109
}

Received January 30, 1989

This investigation was carried out to develop a convenient alternative method for examining the performance and determining the dead time of a stopped-flow fluorometer. We examined the kinetics for the formation of the fluorescent $\mathbf{M g}^{2+}-8$-hydroxyquinoline chelate in aqueous solutions. The reversible association of the $\mathrm{Mg}^{2+}$ ion with 8-hydroxyquinoline is a second-order process whose on and off rate constants are dependent on $\mathrm{pH}$. We estimated that the $\mathrm{Mg}^{2+}$ ion chelate has a fluorescence quantum yield of 0.02 in aqueous solutions. Using this reaction we measured the dead time of a stopped-flow fluorometer at different $\mathrm{pH}$ values. Measurements of the dead time were found to be reproducible and accurate. The $\mathrm{Mg}^{2+}-\mathrm{8}$-hydroxyquinoline reaction fulfills the requirements for a convenient test reaction for dead time measurement of stopped-flow fluorometers. Although the usefulness of the reaction is primarily to determine the dead times of stopped-flow instruments operating in the fluorescence mode, the reaction can also be used for testing an instrument operating in the absorbance mode. 1989 Academic Press, Inc.

The determination of the dead time of a stopped-flow instrument is critical for the evaluation of the range of biological and chemical phenomena that can be analyzed kinetically. Several test reactions have been developed for measuring the dead times of stopped-flow spectrophotometers (1-5). However, suitable reactions for testing an instrument operating in the fluorescence mode are not as numerous. The binding of 8-anilino-1-naphthalenesulfonic acid (ANS) ${ }^{3}$ to bovine serum albumin

\footnotetext{
${ }^{1}$ This research was supported by grants from the U.S. Public Health Service, GM 11106 (V.M.) and GM 20877 (D.P.B.).

${ }^{2}$ To whom correspondence should be addressed.

${ }^{3}$ Abbreviations used: ANS, 8-anilino-1-naphthalenesulfonic acid; BSA, bovine serum albumin; NATA, $N$-acetyltryptophanamide; NBS, $N$-bromosuccinamide.
}

(BSA) $(6,7)$ and the reaction between $N$-acetyltryptophanamide (NATA) and $N$-bromosuccinamide (NBS) (8) have been used for measuring the performance of stopped-flow fluorometers. Unfortunately the ANSBSA reaction has its own disadvantages (8) and the utility of the NATA-NBS reaction is slightly reduced due to the instability of NBS in aqueous solution.

Many sensitive fluorometric assays for metal ions involve the formation of metal chelates that exhibit specific fluorescence characteristics (9). The fluorometric determination of the magnesium ion in serum and urine using 8-hydroxyquinoline as a reagent is a standard clinical procedure (10). In this report, a detailed description of the kinetics for the formation of the fluorescent $\mathrm{Mg}^{2+}$ 8-hydroxyquinoline chelate is presented along with application of this kinetically characterized system to the reliable measurement of the dead time of a stopped-flow fluorometer.

\section{MATERIALS AND METHODS}

Chemicals. 8-Hydroxyquinoline was purchased from Sigma Chemical Co. and quinine sulfate dihydrate from Merck \& Co. They were both used without any further purification. Magnesium chloride hexahydrate (analytical reagent) was from Mallinckrodt.

Solutions and buffers. A $5 \mathrm{mM}$ stock solution of 8hydroxyquinoline in acetonitrile was prepared and stored at $5^{\circ} \mathrm{C}$ in a dark glass bottle. Its concentration was determined using an extinction coefficient of 2600 $\mathrm{M}^{-1} \mathrm{~cm}^{-1}$ at $306 \mathrm{~nm}$ in $0.1 \mathrm{M}$ Tris-Cl, $\mathrm{pH} 9.0$ (11). A 0.1 $\mathrm{M}$ stock solution of $\mathrm{MgCl}_{2}$ in distilled water was standardized with a silver nitrate solution using the Mohr method (12). Buffers were $0.1 \mathrm{M}$ Tris titrated to the appropriate $\mathrm{pH}$ with $\mathrm{HCl}$. All buffers were filtered.

Static absorbance and fuorescence measurements. Absorbance measurements were made with a HewlettPackard diode array spectrophotometer (HP 8452A) and fluorescence spectra were recorded with a ratio spec- 
trofluorometer designed and built by one of us (D.P.B.) and Mr. Gordon S. Ford (13).

Measurement of fluorescence quantum efficiency. The relative quantum yield of fluorescence of the $\mathrm{Mg}^{2+}-$ 8-hydroxyquinoline chelate was measured using the comparative method described by Parker and Rees (14). In this procedure the true fluorescence emission spectrum of a compound is used to obtain its fluorescence efficiency by comparison with a substance of known quantum yield using the equation

$$
Q_{1} / Q_{2}=\left(F_{1} / F_{2}\right)\left(A_{2} / A_{1}\right)
$$

where the ratios of quantum yields, $Q$, are related to the total corrected fluorescence emissions, $F$, and the absorbances at the exciting wavelength of two fluorescent compounds. Quinine sulfate in $0.1 \mathrm{~N} \mathrm{H}_{2} \mathrm{SO}_{4}$ with a quantum yield of 0.70 was used as a reference compound (15).

The corrected fluorescence emission of quinine sulfate and 8-hydroxyquinoline chelate were recorded using an SLM 8000 spectrofluorometer at an exciting wavelength of $360 \mathrm{~nm}$. The areas under the corrected fluorescence emission spectra were determined by cutting out and weighing the recorder paper. This procedure yielded quantum yield values with a precision of $\pm 2 \%$.

Stopped-flow apparatus. Rapid reactions were performed in a stopped-flow apparatus designed for absorbance and fluorescence measurements. The stopped-flow unit was from Kinetic Instruments, Inc. (Ann Arbor, MI) and the detection system was built by one of us (D.P.B.) and Mr. Gordon S. Ford. In the fluorescence mode a Schoeffel 150-W xenon arc lamp (Schoeffel Instrument Corp., Westwood, NJ) with a stabilized power supply provided the excitation source with a Schoeffel monochromator for selection of the exciting wavelength (12 nm bandpass). Fluorescence emission, selected through appropriate filter(s), was collected at right angles to the incident light. A $20-\mathrm{W}(6 \mathrm{~V})$ tungsten-halogen lamp (Osram) was used for absorbance measurements and the wavelength of interest was selected with a Bausch \& Lomb monochromator (3 $\mathrm{nm}$ bandpass). The optical path length of the flow cell in the absorbance mode is $2.5 \mathrm{~mm}$. Reaction signals (absorbance or fluorescence) were detected with a Hamamatsu photomultiplier tube (R928) and processed with a photometer. The kinetic data were recorded with a transient recorder (Physical Data, Inc., Model 514A) and visualized by display on a Type 503 oscilloscope (Tektronix, Inc.) and on an $\mathrm{X}-\mathrm{Y}$ recorder. Observed reaction rates were determined directly from the kinetic traces with the aid of an analog computer that converted the data into logarithmic form. The analog computer was designed by one of us (D.P.B.) and Mr. Gordon S. Ford at the University of Michigan.
Rapid kinetic experiments. All experiments were carried out at $25^{\circ} \mathrm{C}$; the reservoir syringe containing the 8 hydroxyquinoline solution was wrapped in aluminum foil to prevent potential light damage. For fluorescence measurcment a solution of $100 \mu \mathrm{M} 8$-hydroxyquinoline in buffer was mixed with an equal volume of solutions containing various concentrations of $\mathrm{MgCl}_{2}$. Concentrations of $\mathrm{MgCl}_{2}$ were at least 10 times that of 8-hydroxyquinoline to maintain pseudo-first-order conditions. The excitation monochromator was adjusted to $360 \mathrm{~nm}$ and the emitted light filtered through an Esco GG-400 cutoff filter which cuts off light below $400 \mathrm{~nm}$ (Esco Products, Inc., Oak Ridge, NJ). The photometer time constant was $0.1 \mathrm{~ms}$. Under the conditions used, the $\mathrm{Mg}^{2+}-8$-hydroxyquinoline chelate has an absorbance of 0.03 at $360 \mathrm{~nm}$ so that inner-filter effects can be neglected (16). In the absorbance mode a solution of $500 \mu \mathrm{M}$ 8-hydroxyquinoline was mixed with solutions of $\mathrm{MgCl}_{2}$ under pseudo-first-order conditions. Formation of the $\mathrm{Mg}^{2+}$ chelate was followed at $360 \mathrm{~nm}$.

Data and error analysis. A linear least-squares fit was used to select the best straight line through the experimental data points. A weighting factor was introduced in the computations to account for variation in the individual standard deviations and was calculated according to equations described in (17). The uncertainty in the determination of the parameters, expressed as standard deviation, was also obtained.

\section{RESULTS}

Reaction between 8-hydroxyquinoline and magnesium ion. Watanabe et al. (16) and Näsänen (18) have made extensive spectrophotometric, potentiometric, and fluorometric studies on the physical properties of 8-hydroxyquinoline metal ion chelates in aqueous solution. Their work demonstrated that in the $\mathrm{pH}$ range of 7.2 to $9.0,8$-hydroxyquinoline and $\mathrm{Mg}^{2+}$ combine reversibly to form a stable fluorescent chelate (1:1 complex) with dissociation constants greatly dependent on $\mathrm{pH}$. The $\mathrm{Mg}^{2+}-8$-hydroxyquinoline complex fluoresces maximally at $530 \mathrm{~nm}$ upon excitation at $360 \mathrm{~nm}$ (16). The spectral characteristics of the fluorescent chelate are depicted in Fig. 1. Using the comparative procedure of Parker and Rees (14), we determined the quantum yield of these complexes as 0.02 in $0.1 \mathrm{M}$ Tris-Cl, pH 8.5.

The overall reaction can be described by the equilibrium

$$
\mathrm{Mg}^{2+}+\mathrm{HQ} \underset{k_{2}}{\stackrel{k_{1}}{\rightleftarrows}} \mathrm{MgQ}^{+}+\mathrm{H}^{+}, \quad K_{d}=k_{2} / k_{1},
$$

where HQ denotes the protonated form of 8-hydroxyquinoline and $k_{1}$ and $k_{2}$ are, respectively, the forward and reverse rate constants for the formation of the complex.

The observed rate of formation of the chelate is represented by the equation $k_{\text {obs }}=k_{1}\left[\mathrm{Mg}^{2+}\right]+k_{2}$. Under 

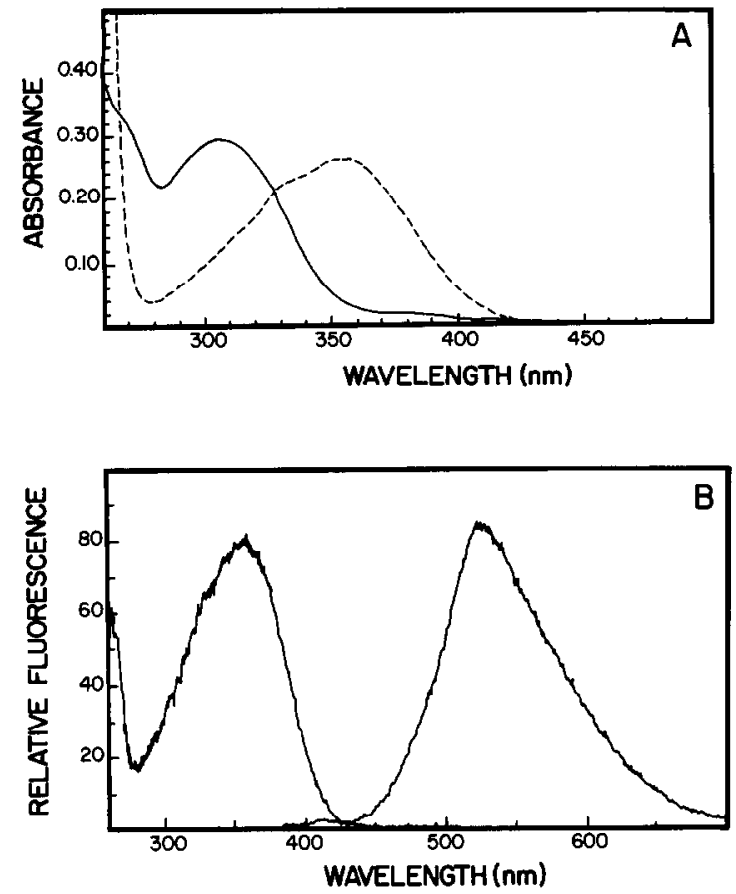

FIG. 1. The spectral properties of the $\mathrm{Mg}^{2+}-8$-hydroxyquinoline complex. (A) The absorption spectrum of a solution of 8-hydroxyquinoline $(112 \mu \mathrm{M})(-)$ changes dramatically upon addition of a saturating concentration of $\mathrm{Mg}^{2+}$ ions ( $\left.29 \mathrm{mM}\right)(---)$. The buffer is $0.1 \mathrm{M} \mathrm{Tris}-\mathrm{Cl}$, pH 8.5, and measurements were made in a $1-\mathrm{cm}$ cell and at $25^{\circ} \mathrm{C}$. (B) The excitation and the apparent fluorescence emission spectra of the $\mathrm{Mg}^{2+}-8$-hydroxyquinoline chelate are shown. Spectra recorded in 0.1 $\mathrm{M}$ Tris-Cl, $\mathrm{pH} 8.5$, and at $25^{\circ} \mathrm{C}$.

pseudo-first-order conditions $k_{\mathrm{obs}}$ is linearly dependent on the magnesium ion concentration and the rate constants, $k_{1}$ and $k_{2}$, are, respectively, equal to the slope and intercept values of a plot relating $k_{\mathrm{obs}}$ to $\left[\mathrm{Mg}^{2+}\right]$.

The linear relationship of the observed rate of formation of the fluorescent chelate with magnesium ion concentration in Tris buffer at $\mathrm{pH} 8.5$ is shown in Fig. 2 . The rate constants, $k_{1}$ and $k_{2}$, were evaluated as 6.8 $( \pm 0.3) \times 10^{4} \mathrm{M}^{-1} \mathrm{~s}^{-1}$ and $40 \pm 7 \mathrm{~s}^{-1}$, respectively. By appropriately selecting the magnesium ion concentration it is possible to cover values of $k_{\mathrm{obs}}$ ranging from a limiting value of $k_{2}$ to an upper limit of approximately $750 \mathrm{~s}^{-1}$ (the upper value being set by instrumental limitations). Using this approach we determined the values of $k_{1}$ and $k_{2}$ at several other $\mathrm{pH}$ values. These kinetic constants are summarized in Table 1.

As complementary experiments we performed a similar kinetic study in the absorbance mode by following formation of the complex at $360 \mathrm{~nm}$. The rate constants evaluated in the absorbance mode are in reasonable agreement with those fluorometrically determined under the same conditions (Table 1 ).

The dissociation constants of the $\mathrm{Mg}^{2+}-8$-hydroxyquinoline complex calculated from the experimental val-

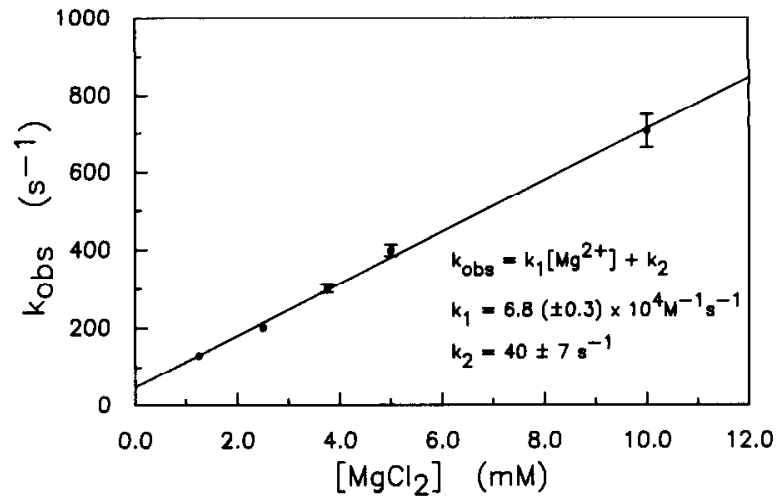

FIG. 2. The effect of magnesium ion concentration on the observed rate of formation of the $\mathrm{Mg}^{2+}-8$-hydroxyquinoline complex. $8-\mathrm{Hy}$ droxyquinoline $(100 \mu \mathrm{M})$ was reacted with solutions containing various concentrations of $\mathrm{MgCl}_{2}$ and the rate of formation of the chelate was followed fluorometrically in a stopped-flow apparatus as described under Materials and Methods. The experiment was performed in $0.1 \mathrm{M}$ Tris- $\mathrm{Cl}, \mathrm{pH} 8.5$, and at $25^{\circ} \mathrm{C}$. Each point represents the average value of 10 determinations with its standard deviation.

ues of $k_{1}$ and $k_{2}$ are in close agreement with those from Fig. 8 of Watanabe et al. (16).

Determination of the dead time of the stopped-flow fluorometer. A measure of the dead time $\left(t_{\mathrm{d}}\right)$ of the instrument can be obtained from stopped-flow traces of a first-order reaction of known rate $k$ using the relationship (19)

$$
k t_{\mathrm{d}}=2.303 \log \left(F_{\mathrm{tot}} / F_{\mathrm{obs}}\right)
$$

where $F_{\text {tot }}$ is the total change in fluorescence intensity and $F_{\text {obs }}$ is the magnitude of the observed change.

\section{TABLE 1}

Magnitude of the Rate Constants $k_{1}$ and $k_{2}$ for the Reversible Association of $\mathrm{Mg}^{2+}$ Ion with 8-Hydroxyquinoline and the Calculated Dead Time Values for the Stopped-Flow Instrument

\begin{tabular}{|c|c|c|c|c|}
\hline $\mathbf{p} \mathbf{H}^{a}$ & Mode $^{b}$ & $\begin{array}{c}k_{1}^{c} \\
\left(10^{-3} \mathrm{M}^{-1} \mathrm{~s}^{-1}\right)\end{array}$ & $\begin{array}{c}k_{2} \\
\left(\mathrm{~s}^{-1}\right)\end{array}$ & $\underset{(\mathrm{ms})}{\text { Dead time }}\left(t_{\mathrm{d}}\right)$ \\
\hline 7.5 & $\begin{array}{l}\mathrm{F} \\
\mathrm{A}\end{array}$ & $\begin{array}{l}18 \pm 1 \\
15 \pm 2\end{array}$ & $\begin{array}{l}120 \pm 10 \\
130 \pm 10\end{array}$ & $\begin{array}{l}1.0 \pm 0.1 \\
1.4 \pm 0.3\end{array}$ \\
\hline 8.0 & $\begin{array}{l}\mathrm{F} \\
\mathrm{A}\end{array}$ & $\begin{array}{l}26 \pm 1 \\
22+1\end{array}$ & $\begin{array}{l}72 \pm 4 \\
73 \pm 6\end{array}$ & $\begin{array}{l}1.0 \pm 0.1 \\
1.4 \pm 0.2\end{array}$ \\
\hline 8.5 & $\begin{array}{l}\text { F } \\
\text { A }\end{array}$ & $\begin{array}{l}67 \pm 4 \\
59 \pm 2\end{array}$ & $\begin{array}{l}40 \pm 10 \\
40 \pm 10\end{array}$ & $\begin{array}{l}1.2 \pm 0.1 \\
1.4 \pm 0.2\end{array}$ \\
\hline 9.0 & $\begin{array}{l}\mathbf{F} \\
\mathrm{A}\end{array}$ & $\begin{array}{l}200 \pm 10 \\
170 \pm 10\end{array}$ & $\begin{array}{l}34 \pm 4 \\
50 \pm 4\end{array}$ & $\begin{array}{l}1.0 \pm 0.1 \\
1.2 \pm 0.1\end{array}$ \\
\hline
\end{tabular}

${ }^{a}$ Experiments were carried out in $0.1 \mathrm{M}$ Tris-Cl buffers of appropriate $\mathrm{pH}$ and at $25^{\circ} \mathrm{C}$.

${ }^{b}$ Detection was by fluorescence (F) or absorbance (A).

${ }^{c}$ Each rate value represents the average determination from two kinetic experiments (such as shown in Fig. 2) with its standard deviation. 


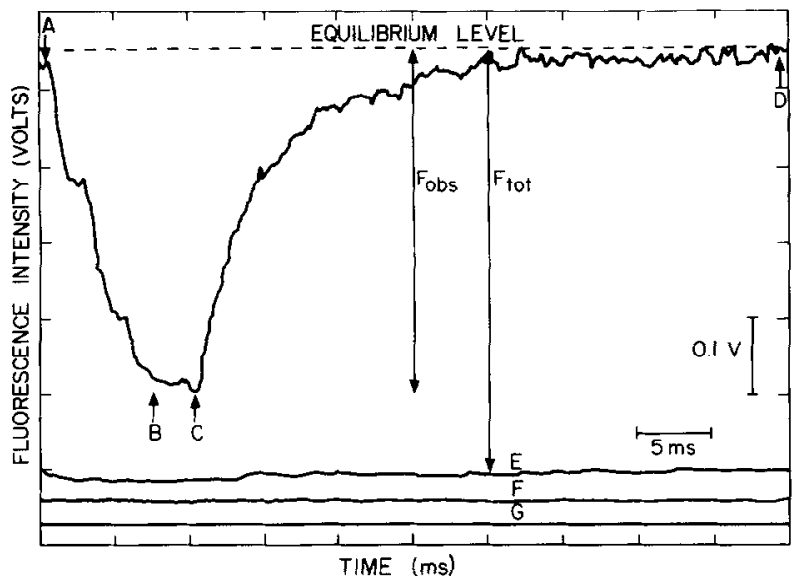

FIG. 3. Time course of the formation of the $\mathrm{Mg}^{2+}-8$-hydroxyquinoline chelate. A solution of 8 -hydroxyquinoline $(100 \mu \mathrm{M})$ was mixed in the stopped-flow apparatus with a $5 \mathrm{mM}$ solution of $\mathrm{MgCl}_{2}$ at $25^{\circ} \mathrm{C}$ in $0.1 \mathrm{M}$ Tris buffer, $\mathrm{pH}$ 8.5. The increase in fluorescence resulting from formation of the complex was recorded. Optimal performance of the stopped-How instrument is illustrated on the reaction curve by the sequence of letters $\mathrm{A}$ to $\mathrm{D}$. Point $\mathrm{A}$ is the beginning of flow and point $\mathrm{C}$ is where flow stops. The previous cell contents are flushed with fresh reaction mixture (region $\mathrm{A}-\mathrm{B}$ ) and the fluorescence signal reaches a steady-state level (region B-C) before flow stops (point C). It is important to ensure that a sufficient volume of reactants is mixed such that previously reacted reagents are flushed from the cell. This can be verified by the observation of a small interval of steady-state fuorescence as shown in the $\mathrm{B}-\mathrm{C}$ region of this figure. Region $\mathrm{C}-\mathrm{D}$ shows the progress of the reaction to equilibrium (point $D$ ). The fluorescence baselines denoted by the letters $\mathrm{E}, \mathrm{F}$, and $\mathrm{G}$ are $\mathrm{E}, 8$-hydroxyquinoline in buffer; $\mathrm{F}$, buffer (0.1 M Tris, $\mathrm{pH} 8.5$ ); G, dark current (electronic background). The observable fluorescence change $\left(F_{\text {obs }}\right)$ and the total change in fluorescence $\left(F_{\text {tot }}\right)$ are also illustrated in the figure.

After rearrangement and substitution of $k_{1}\left[\mathrm{Mg}^{2+}\right]$ $+k_{2}$ for $k$, the following equation results:

$$
\log F_{\mathrm{obs}}=-0.434 k_{1} t_{\mathrm{d}}\left[\mathrm{Mg}^{2+}\right]+\left(\log F_{\mathrm{tot}}-0.434 k_{2} t_{\mathrm{d}}\right) . \quad \text { [3] }
$$

This equation predicts that a value for $t_{\mathrm{d}}$ can be derived from the slope of a plot relating $\log F_{\mathrm{obs}}$ to $\left[\mathrm{Mg}^{2+}\right]$, assuming that the rate constant $k_{1}$ has been previously determined.

Experimentally, the magnitude of $F_{\text {tot }}$ is obtained by subtracting the fluorescence of 8-hydroxyquinoline in the absence of $\mathrm{Mg}^{2+}$ from the final fluorescence signal in the stopped-flow instrument after reaction with $\mathrm{Mg}^{2+}$. The actual change observed in the apparatus, $F_{\text {obs }}$, is measured directly from stopped-flow traces as shown in Fig. 3.

Due to limitations in accurately measuring reaction rates above $750 \mathrm{~s}^{-1}$ in the stopped-flow instrument and to the fact that $K_{d}$ values for the $\mathrm{Mg}^{2+}-8$-hydroxyquinoline complexes are relatively high, complete saturation of the 8-hydroxyquinoline could not be attained in the stopped-flow apparatus for most magnesium ion concentrations employed. This implies that $F_{\text {tot }}$ values differ with changing magnesium ion concentrations. A slight modification to Eq. [3] was necessary to accommodate this problem.

Thus for each magnesium ion concentration, we defined $F_{\text {obs }}^{\prime}$ as the ratio of $F_{\text {obs }}$ to $F_{\text {tot }}$ and $F_{\text {tot }}^{\prime}$ as being equal to unity. After substitution of these parameters into Eq. [3], the following equation results:

$$
\log F_{\text {obs }}^{\prime}=-0.434 k_{1} t_{\mathrm{d}}\left[\mathrm{Mg}^{21}\right]-0.434 k_{2} t_{\mathrm{d}}
$$

If $F_{\mathrm{obs}}^{\prime}$ is measured as a function of $\left[\mathrm{Mg}^{2+}\right]$, a plot of $\log F_{\text {obs }}^{\prime}$ vs $\left[\mathrm{Mg}^{2+}\right]$ will have a slope equal to $-0.434 k_{1} t_{\mathrm{d}}$ from which $t_{\mathrm{d}}$ can be extracted. Such an analysis performed on stopped-flow results obtained in $0.1 \mathrm{M}$ Tris$\mathrm{Cl}, \mathrm{pH} 8.5$, and at $25^{\circ} \mathrm{C}$ is presented in Fig. 4. The value for $t_{\mathrm{d}}$ at $\mathrm{pH} 8.5$ is listed in Table 1 along with $t_{\mathrm{d}}$ determinations at other $\mathrm{pH}$ values.

An alternative method of data analysis is to extrapolate the semilogarithmic plots of kinetic traces to times before that of initial observation in the stopped-flow apparatus. Extrapolated plots obtained at various concentrations of the reactant in excess will intersect at true zero time. The difference in time between the extrapolated intersection point and the point of initial observation is the instrumental dead time $(2,8,20)$. This alternate method of analysis yielded comparable dead time values as those presented in Table 1 for the fluorescence and absorbance data at $\mathrm{pH} 8.5$.

\section{DISCUSSION}

Our kinetic investigation of the $\mathrm{Mg}^{2+}-8$-hydroxyquinoline chelate along with our ability to reproduce dissociation constants that Watanabe et al. (16) have deter-

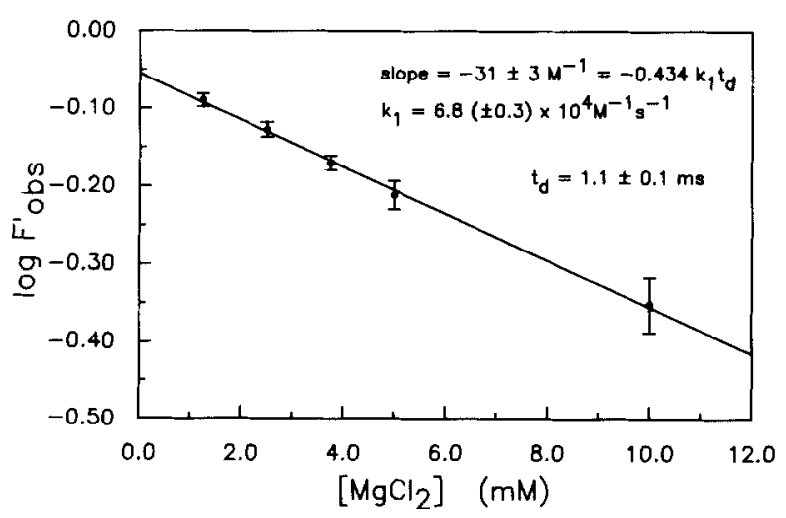

FIG. 4. Graphical determination of the dead time of the stoppedflow fluorometer. By analysis of the kinetic data for the formation of the $\mathrm{Mg}^{2+}-8$-hydroxyquinoline complex, $F_{\text {obs }}^{\prime}$, which is defined as $F_{\text {obs }}$ / $F_{\text {tot }}$, is calculated for each magnesium ion concentration. From the slope of a plot of $\log F_{\mathrm{obs}}^{\prime}$ vs $\left[\mathrm{Mg}^{2+}\right]$ a value for $t_{\mathrm{d}}$ can be derived. This analysis was performed on experimental stopped-flow data obtained in $0.1 \mathrm{M}$ Tris- $\mathrm{Cl}, \mathrm{pH} 8.5$, and at $25^{\circ} \mathrm{C}$. Each $F_{\text {obs }}^{\prime}$ value represented is the average from 10 stopped-flow traces with its standard deviation. 
mined by fluorometric titration reinforce and confirm that the reversible association of magnesium ion with 8hydroxyquinoline is a second-order reaction in the $\mathrm{pH}$ range of 7.2 to 9.0. Evidence exists that at $\mathrm{pH}$ values above 9.5 and at high ligand concentration, higher order complexes of $\mathrm{Mg}^{2+}$ and 8-hydroxyquinoline predominate $(16,18)$. The formation of these rather insoluble complexes is negligible under our experimental conditions and consequently did not interfere with our investigation.

The $\mathrm{Mg}^{2+}$-8-hydroxyquinoline reaction provides a reliable method for the fluorometric measurement of dead time. This is illustrated by the fact that although $k_{1}, k_{2}$, and the range of $\mathrm{Mg}^{2+}$ ion concentration used differ for each $\mathrm{pH}$, our determined dead time values are very reproducible in a $\mathrm{pH}$ range of 7.5 to 9.0. Moreover, these values are the same as determined with this stoppedflow instrument in the absorbance mode $(1.1 \pm 0.1 \mathrm{~ms}$, data not shown) using the reduction of 2,6-dichlorophenolindophenol by ascorbic acid $(1,2)$.

Discrepancies exist between the fluorescence and the absorbance results (Table 1). First, the value of $k_{1}$ in the absorbance mode is approximately $15 \%$ smaller in magnitude than that of $k_{1}$ in the fluorescence mode. Second, the dead time values in the absorbance mode seem slightly overestimated compared to the fluorometrically determined values. Determinations of dead time in the absorbance mode with the chelation reaction are consequently less reliable. Although these results imply that the reaction may be more complex than the fluorescence data indicate, we are unable to provide a rational explanation for these differences.

We would like to point out that many chelation reactions exist for the fluorometric determinations of inorganic metal ions (9) and that any of these reactions are potential test reactions for determining the dead time of stopped-flow fluorometers. We chose the $\mathrm{Mg}^{2+}-8$-hydroxyquinoline reaction for several reasons: (a) 8-hydroxyquinoline shows a high degree of specificity for $\mathrm{Mg}^{2+}$ ions compared to other cations (e.g., $\mathrm{Ca}^{2+}$ and $\mathrm{Zn}^{2+}$ ), (b) the reagents are inexpensive and available commercially, (c) the reactants and the products of the reaction are stable under the conditions used, and (d) the $\mathrm{Mg}^{2+}-8$-hydroxyquinoline chelate has been thoroughly studied in the literature.
The $\mathrm{Mg}^{2+}-8$-hydroxyquinoline reaction is a convenient method for testing the performance of stoppedflow fluorometers. In the $\mathrm{pH}$ range studied this reaction is characterized by rates easily accessible by stoppedflow techniques and a range of $\mathrm{Mg}^{2+}$ ion concentration convenient to the experimenter. Although the major application of this reaction is to measure the dead time and overall performance of a stopped-flow instrument operating in the fluorescence mode, the same reaction can be used (with limitations discussed above) for testing an apparatus operating in the absorbance mode.

\section{ACKNOWLEDGMENT}

We are grateful to Dr. Lawrence M. Schopfer for helpful discussions.

\section{REFERENCES}

1. Tonomura, B., Nakatani, H., Ohnishi, M., Yamaguchi-Ito, J., and Hiromi, K. (1978) Anal. Biochem. 84, 370-383.

2. Hammes, G. G., and Haslam, J. L. (1968) Biochemistry 7, 15191524.

3. Harvey, R. A. (1969) Anal. Biochem. 29, 58-67.

4. Nakamura, T. (1971) J. Biochem. 70, 961-966.

5. Chance, B. (1974) in Techniques of Chemistry (Weissberger, A., Ed.), Vol. 6, Part 2, pp. 5-62, Wiley, New York.

6. Stewart, J. E., Durrum Application Notes No. 7, Durrum Instrument Corporation, Sunnyvale, CA.

7. Gibson, Q. H. (1969) in Methods in Enzymology (Kustin, K., Ed.), Vol. 16, p. 216, Academic Press, New York.

8. Peterman, B. F. (1979) Anal. Biochem. 93, 442-444.

9. Udenfriend, S. (1969) Fluorescence Assay in Biology and Medicine, Vol. 2, p. 485, Academic Press, New York.

10. Thiers, R. E. (1965) in Standard Methods of Clinical Chemistry (Meites, S., Ed.), Vol. 5, p. 131, Academic Press, New York.

11. Burton, K. (1959) Biochem. J. 71, 388-395.

12. Christian, G. D. (1980) Analytical Chemistry, 3rd ed., p. 235, Wiley, New York.

13. Moore, E. G., Cardemil, E., and Massey, V. (1978) J. Biol. Chem. 253, 6413-6422.

14. Parker, C. A., and Rees, W. T. (1960) Analyst 85, 587-600.

15. Scott, T. G., Spencer, R. D., Leonard, N. J., and Weber, G. (1970) J. Amer. Chem. Soc. 92, 687-695.

16. Watanabe, S., Frantz, W., and Trottier, D. (1963) Anal. Biochem. 5, 345-359.

17. Bevington, P. R. (1969) Data Reduction and Frror Analysis for the Physical Sciences, p. 99, McGraw-Hill, New York.

18. Näsänen, R. (1952) Acta Chem. Scand. 6, 352-357.

19. Hiromi, K. (1979) Kinetics of Fast Enzyme Reactions, p. 99, Wiley, New York.

20. Ballou, D. P., and Palmer, G. (1974) Anal. Chem. 46, 1248-1253. 